\title{
Phantasmagoric Venues from the West to the East: Studies on the Great Exhibition (1851) and the Taiwan Exhibition (1935)
}

\author{
Ping-Sheng $\mathrm{Wu}^{*^{1}}$ and Min-Fu Hsu ${ }^{2}$ \\ ${ }^{1}$ Ph.D. Candidate, National Cheng-Kung University, Taiwan \\ ${ }^{2}$ Professor, National Cheng-Kung University, Taiwan
}

\begin{abstract}
This research focuses primarily on the Taiwan Exhibition (1935) with particular reference to its archetype, the Great Exhibition (1851). Through these, this paper considers the concepts and appearance of world exhibitions. It also discusses how they became a spatial venue to show "modernity" and "colonialism" in the nineteenth and early twentieth centuries.

It starts with a description of the history and concepts of world exhibitions, and follows with a discussion of modernity and colonialism. Since the nineteenth century, world exhibitions have been regarded as the most meaningful invention of "modernity". These not only present the exhibition of commodities, but also reflect the turning point in industrialization. However, camouflaged by the cover of modernization, world exhibitions essentially revealed the ideologies of imperialism and colonialism.

Although postdating the Great Exhibition by almost eighty years, this essay will suggest that the Taiwan Exhibition, the greatest exhibition held in Japanese colonial territories, conveyed the same ideologies of modernity and colonialism. It seems that there are unexpected similarities between these two events in completely different times, 1851 and 1935, and places, the west and the east.
\end{abstract}

Keywords: modernity; colonialism; the great exhibition; the Taiwan exhibition

\section{Introduction}

World exhibitions have been regarded as the most meaningful invention of "modernity", famously defined by Walter Benjamin as "the world dominated by its phantasmagorias" (Hermansen \& Hvattum, 2004: xi), since the nineteenth century. These present not only the exhibition of commodities, but also the expansion of products and capital markets. Moreover, from world exhibitions emerges the meaning of celebrating national events, as well as reflecting the turning point in industrialization. However, camouflaged by the cover of modernization, world exhibitions can represent the ideologies of nationalism, imperialism and colonialism.

This research focuses mainly on the Taiwan Exhibition (1935) while it also looks back to its archetype, the Great Exhibition (1851). The main reasons for selecting these two cases are twofold. The Great Exhibition (1851) in London was the world's first international exhibition, which not only grew to become an archetype of world exhibitions but also

\footnotetext{
*Contact Author: Ping-Sheng Wu, Department of Architecture, National Cheng-Kung University,

No.1, Ta-Hsueh Road, Tainan 701, Taiwan

Tel: +886-6-2083973 Fax: +886-6-2747819

e-mail: wuben128@seed.net.tw

(Received April 17, 2006; accepted July 31, 2006)
}

was regarded as one of the most significant sources of modern architecture. Thereafter, it provided valuable experiences for Japan, the only non-Western colonial empire, to hold exhibitions in her homeland and colonies. In addition, the Taiwan Exhibition (1935) in Taipei was the greatest exhibition held in Japanese colonial territories. From the viewpoints of Taiwanese people, though under colonial rule, it was an important event/venue in which to experience the concept of modernity spatially and mentally.

Firstly, the discussion will focus on the concepts of exhibitions, modernity and colonialism. Secondly, it will trace back to the origin of modern world exhibition, the Great Exhibition of 1851 in London. Thirdly, this essay will mainly concentrate on discussing how the Taiwan Exhibition was transplanted by the Japanese in 1935; and it will end with a discussion on the meanings of the Taiwan Exhibition and the Great Exhibition.

\section{The Concept and History of World Exhibitions}

The first international exhibition, known as the Great Exhibition, was held in London in 1851. Over the last 150 years, world exhibitions have made an important contribution to the history of modernization in Western society. The main objective of the exhibitions in the process of modernization was threefold: production, trade and consumption, in addition to socio-cultural aspects (Wesemael, 2001:21). 
The historian Eric Hobsbawn pointed out that world exhibitions contained a "great new ritual of selfcongratulation," celebrating economic and industrial triumphs (Çelik, 1992). With the rise of imperialism and colonialism, however, world exhibitions, which initially disseminated innovations and improved international trade opportunities, were transformed into venues for the display of the national identity and power of colonial states. Imperialism and colonialism played important roles in this growth, redefining the global power structure and simultaneously stimulating widespread interest in the non-Western world. It can be said that while the Western world exported its industrial revolution to the rest of the globe, it also began to import information about other cultures (ibid). Nevertheless, from the viewpoint of the colonies, this kind of "modernity" is widely regarded as "colonial modernity" instead of only "modernity".

\section{Modernity and Colonialism}

"Modernity" is a phenomenon that first appeared in eighteenth-century Western Europe and then spread to other parts of the world (Shin \& Robison, 1999: 9). It is generally associated with ideas such as Enlightenment, rationalism, citizenship, industrialism, nationalism, and capitalism. The Industrial Revolution of England and the social revolution of France as well as the Enlightenment Movement are generally considered major events that shaped the rise and growth of European modernity.

Since the introduction of modernity around the late eighteenth century, one of the possible sites for the study of modernity was the modern metropolis. In 'The painter of modern life' (1863), Baudelaire defined the concept of Modernité. For Marshall Berman, modernity is defined as "a mode of vital experience-experience of space and time, of the self and others, of life's possibilities and perils-that is shared by men and women all over the world today..." Frisby (2004:13) points out that Walter Benjamin's definitions of modernity- "The world dominated by its phantasmagorias ... this is modernity" and "The new in the context of what has always been there"- indicated relations with earlier images of modernity. Furthermore, in 'Paris, the Capital of the Nineteenth Century', Arcades Project and other writings, Benjamin's exploration of Paris as capital of the nineteenth century in the aspects of architecture, streets, figures, representations and media is intended as illumination of the modernity of today (Frisby, 2001:23 \& 2004:13; Gilloch, 1997: 129).

Historically, modernity and colonialism are invisible features of the development of industrial capitalism. It is widely accepted that colonialism or imperialism is quite an important connection in the West and nonWestern relations. It becomes a motive force for the West to introduce the concept of modernity to the world. Originating in the West, however, modernity has taken different forms as it spread to other parts of the world. For some non-western countries or areas at certain times in history, colonization involves westernization as well as purely modernization. Examples include the rule of India and Singapore by Great Britain, control of Indonesia by the Netherlands and Japanese dominance in Taiwan, Korea as well as Manchuria.

In Taiwan, the appearance of modernity was closely associated with external influences. Any discussion of Taiwanese modernity, therefore, must confront the fact of colonialism. Anthony King points out that "Colonialism" can be understood as "the establishment and maintenance, for an extended time, of rule over an alien people that is separate and subordinate to the ruling power" (from King 1976:17, citing Emerson, 1968). It often facilitates economic domination over their resources, labor, and markets. The term also refers to a set of beliefs used to legitimize or promote this system, especially the belief that the mores of the colonizer are superior to those of the colonized. Generally speaking, the formal colonial system, which resulted in movement for national independence by the mid-twentieth century, was the product of a latenineteenth century "spasm of imperial expansion" (Peattie, 1984: 3).

In recent years, there has been much discussion and dispute over the concept of "modernity", in both colonized areas and in the West. This is because in these colonized areas, "modernity" has taken different forms. First appearing in positions: east asia cultures in the autumn of 1993, the term "colonial modernity" has become a "useful innovation" frequently discussed (Barlow, 1997:3). Taiwan's reception of modernity was mediated by a complicated filtering mechanisma process of translation begun a generation earlier in Japan and one that continued in Taiwan under colonial rule. In particular, it was the emergence of Modern Japan and its intrusion into Taiwan that stimulated and provided a direct model for the effort to build a nationstate, which could compete against Western countries, in the late nineteenth century.

In summary, this research will firstly look back at London's Great Exhibition of 1851 and then mainly concentrate on the Taiwan Exhibition held in 1935 during the Japanese colonial period. With them, the ideas of "modernity" and "colonial modernity" will be explored.

\section{The Great Exhibition in $\mathbf{1 8 5 1}$}

The glimpse, through the iron gates of the transept, the warming palms and flowers, the myriads of people filling the galleries and seats around, together with the flourish of trumpets as we entered the building... (Queen Victoria's Personal Diary, $1^{\text {st }}$ May 1851 qtd. in Wesemael, 2001:114-5)

\subsection{About the Great Exhibition}

In the spring of 1851 in London, an event named the "Great Exhibition of the Works of Industry of all 
Nations," usually called the Great Exhibition was opened in May and closed six months later. Witnessed as an event described by Queen Victoria as "The most beautiful and imposing and touching spectacle ever seen." (Hvattum, 2004:124) During this period, it was visited by almost one fifth of Britain's population. The Great Exhibition presented an overview of human inventions in the midst of the industrial revolution: machines and weapons, architecture and art, possible and impossible products of industry, as well as artefacts assembled from the past to present, far and near, comprising more than 100,000 objects from around the world (ibid). In addition, London's Hyde Park and the surrounding streets thronged with people, with the Crystal Palace in the centre as a kind of national monument.

During the nineteenth century, world exhibitions demonstrated a powerful stimulus for engineering and construction. They became examples of modern infrastructural or utilitarian assignments and corresponding engineering aesthetics. The huge exhibition halls demanded whole new methods to accommodate the various displays and numerous visitors. In addition, new materials like glass, iron, and steel made not only wider spanning possible, but were suitable for building quickly and relatively cheaply. The new materials and methods of construction replaced the former architectural crafts and styles.

The prototype of the exhibition pavilion is the multinave basilica. It gave rise to a typically elongated form, sometimes with one or more transepts, divided into long galleries punctuated by free-standing columns. The outer walls were either plastered or left transparent as the Crystal Palace was. Within the exhibition context, the Crystal Palace, which was constructed of iron and glass, has become very famous with the passage of time. At the time of its construction, most architects and engineers agreed with the Palace as a source of a new industrial architecture that adequately represented the features of the modern times. Just as Siegfried Giedion declared, "it was one of the most important sources of modern architecture". (Mattie, 1998; Wesemael, 2001:215)

Joseph Paxton, who was a landscape gardener and horticulturist, designed the Crystal Palace exhibition hall with immense proportions. In order to accommodate the requirement that a group of monumental elm trees in Hyde Park be preserved, Paxton spanned the transept with 108-foot vaulting, making its interior as tall as that of Nôtre Dame in Paris (Mattie, 1998:13). In the meantime, the architect Owen Jones took responsibility for the decoration and painting of Paxton's glasshouse construction. Through an innovative color scheme, Jones made an attempt to give this pavilion "a representative appearance so that one could justifiably talk of a palace or temple." (Wesemael, 2001:159)

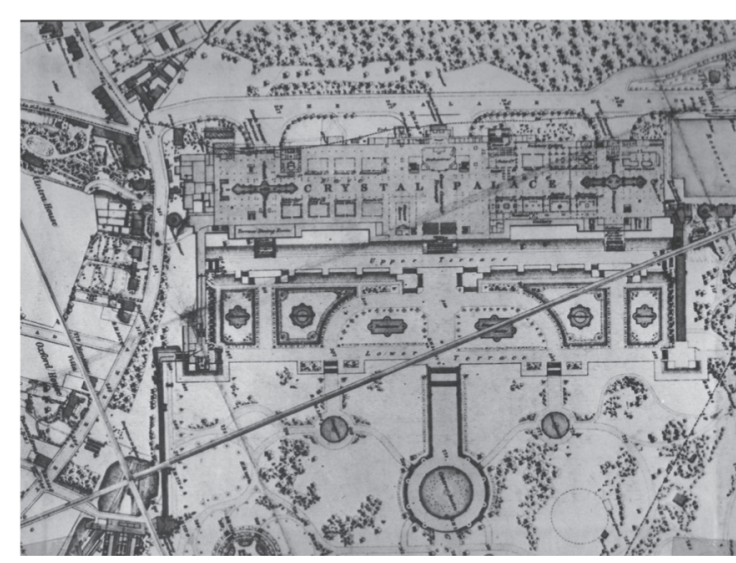

Fig.1. Site Plan of the Great Exhibition in the Hyde Park (Source: Patrick Beaver, 1970)
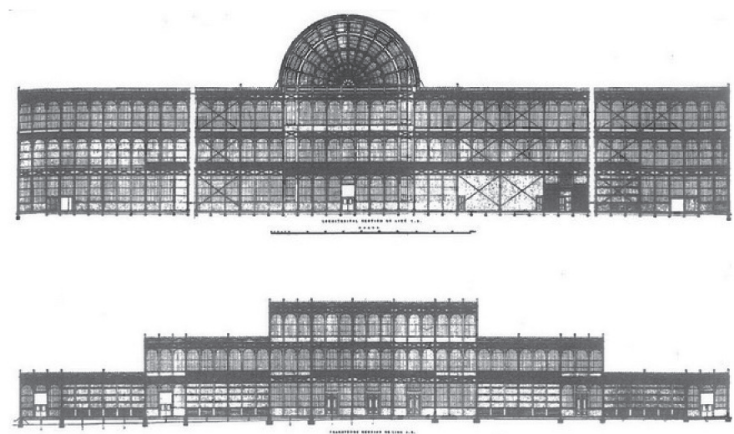

Fig.2. Cross-Sections in Length and Width of the Crystal Palace (Source: Pieter van Wesemael, 2001:171)

According to Prince Albert, one of its patrons, the purpose of this exhibition was to "give a true test and a living picture of the point at which the whole of mankind had arrived in this great task, and a new starting point from which all nations will be able to direct their future exertions." ${ }^{1}$ When entering the Crystal Palace, the visitor first saw the whole palace decorated with flowers and tropical palms. The sunlight made the crystal glimmer and radiated through the iron columns and girders so that the structure almost disappeared. Then, through the south transept, the visitor encountered a twofold starting point; the beginning of the exhibition itself and the "point zero" (Hvattum, 2004:127,). From south to north along the central transept of the palace, they would experience various degrees of 'primitiveness'-from Tunis, through China and the Middle East, to India, Turkey and Egypt. Continually, the impressions of these scenes were reinforced when the visitors arrived at the crystal fountain and could view the building in its full length and breadth along the transepts.

In the exhibition, there were many examples or specimens, illustrations of the best, cheapest, most innovative, or most modern products. For example, there were model houses designed by the "society for improving the labouring classes", and the scale model of a new power system for steamboats. The visitors 
were particularly attracted by a tailor's metal dummy that could adopt any required posture (Wesemael, 2001: 185). Because some items were too large to be transported, many scale models of ships, steam engines, bridges, glasshouses, and churches were on display in the hall.

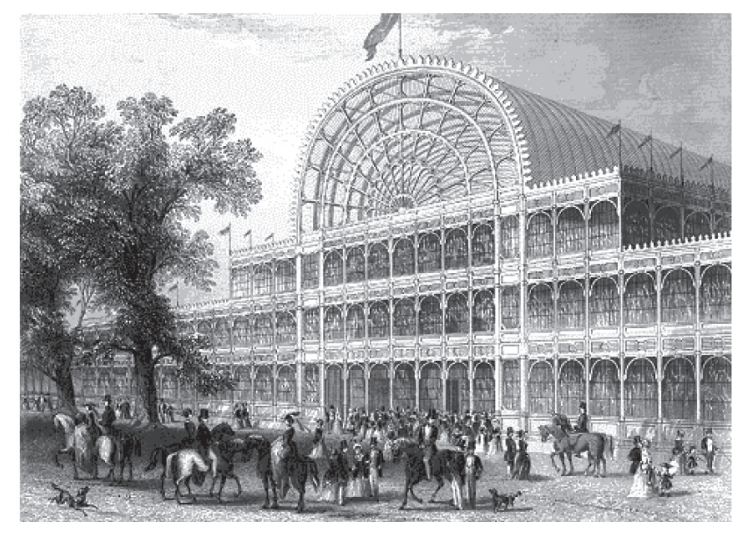

Fig.3. The Visitors to the Great Exhibition outside the North Transept of the Crystal Palace

(Source: University of Maryland Libraries, 2000)

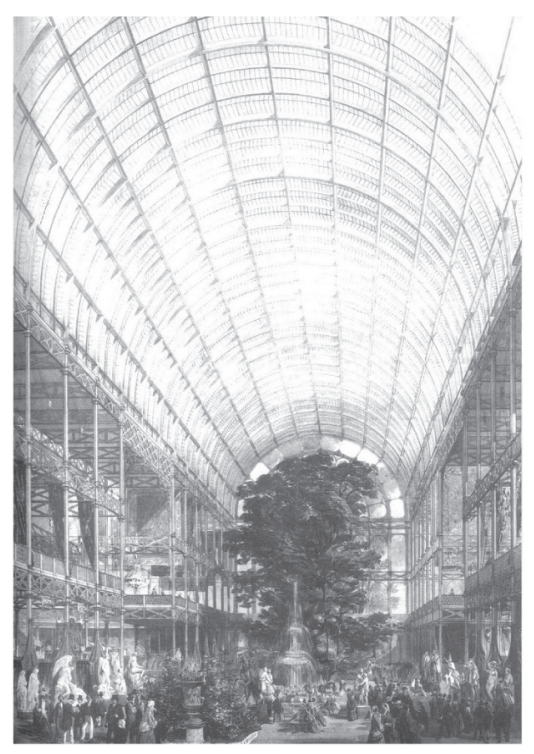

Fig.4. View of the Transept

(Source: Pieter van Wesemael, 2001:169)

In addition, according to various participants, Jones' innovative color scheme "succeeded in the illusory reinforcement of the effect of perspective: the naves of the palace appeared to reach out towards infinity." (Wesemael, 2001: 183) Although the roof and outer walls were covered by canvas, his color scheme guaranteed that the iron and glass pavilion lost only little of its transparency. Moreover, to the British public, Jones' revolutionary colour scheme of red, blue and gold adorned the framework with repeated scenes of the extraordinary world of exotic sections such as those in India, China, Tunisia and Persia. The layout of the transept area itself became a "mixture between a museum, a national monument, and a winter garden" (ibid: 183). All in all, it presented "an encyclopedic overview of human ingenuity in the midst of the unfolding industrial revolution" (Hvattum, 2004: 124).

\subsection{After the Great Exhibition}

Because of its success, the Great Exhibition grew to become the archetype of the world exhibition. Immediately following 1851, the exhibitions in New York (1853), Dublin (1853) and Munich (1854), for example, were more or less copies of the Great Exhibition. The next fully-fledged international exhibition was Exposition Universelle, held in Paris in 1855. Therefore, the Great Exhibition can be seen as a turning point in world history, especially in the industrialization and globalization of the modern world. However, by observing the way the Great Exhibition was laid out, some of its underlying ambitions can be discerned. The arrangement of the exhibition in the main nave represented a developmental line, which led the visitor, east to west, from the new world through the European continent, and finally to encounter the products of the British Empire. This exhibition provided a tour not only through the world but also through world history. It appeared a "carefully choreographed exercise in progressive historiography" (Hvattum, 2004:127).

In fact, the British government seized upon the industrial exhibitions as a propaganda and policy instrument. In domestic events, on the one hand, the government could present itself as a "patron" that stimulated industry, trade, science and education by means of planned policies. On the other, in the context of foreign affairs, the exhibition gave government the opportunity to display its own power. It helped to create the idea and forms of "Great Britain, India, and other Colonies" as well as binding together these polities (Hoffenberg, 2001:20). In other words, as Hoffenberg said, "Exhibitions were at the heart of imperial and national social and commercial enterprises during the Victoria and Edwardian Eras" and "Imperial, colonial, and national inventories were linked at the exhibitions by official tests and jury reports, consumption, tourism, and historical pageants"(ibid: XV). In brief and most importantly, the exhibition became not only an invention of "modernity" but also a symbol of national power for those colonial states.

In 1862, Japan started to participate in the world exhibition, the International Exhibition in London. From that time onwards, Japan, the only non-Western colonial empire in Asia, considered that the exhibitions were not only for demonstrating colonial achievement, but also for competing with Western society. Between 1877 and 1911, five National Exhibitions for Encouraging Trade and Industry were held in Tokyo and Osaka. Apart from those in the homeland, Japan also held exhibitions in her colonial territories. Of these, the Taiwan Exhibition held in Taipei in 1935 was the greatest. 


\section{The Taiwan Exhibition in $\mathbf{1 9 3 5}$}

Go to visit the Exhibition in Taipei! Go with us!

...the road in front of the Taipei Railway Station is overflowing with people going towards the museum, therefore Mr. Dou-Wen feels like a lonely boat without destination... (Zhu, 1936)

\subsection{Before the Taiwan Exhibition}

In the $1870 \mathrm{~s}$, the implications of colonization rapidly impinged on the Japanese consciousness. By 1895, Japan had acquired her first colonial territory, Taiwan, and had thus joined the ranks of the colonial powers. In the words of Goto Shimpei, chief of the Civil Administration Bureau on this island, Taiwan was to be the "colonization university" for Japan's first experiment in colonial rule. For him, Taiwan became first "to demonstrate that Japan was the equal of Western Imperialists and second to transcend Western rule in brining welfare to the conquered territory." (Ching, 2001:17) Among the territories colonized by Japan in Asia and Oceania, Taiwan's colonial period lasted the longest, even though the fifty-year span is but a small period compared with the duration of European colonialism in other parts of the world. However, this new territory became an "essential hinge in the Empire's southern gate" as well as a "symbol of the nation's equality with the West and of its participation in the great work of modernization" (Myers \& Peattie, 1984:82 \& 90).

From 1910 to 1916, the situation in both Taiwan and the rest of the world was changing dramatically. The establishment of the Republic of China and the death of Japanese Emperor Meiji in 1912 were two turning points of these two empires. Moreover, with the outbreak of World War I in Europe in 1914, the influences of colonial states in Asia were affected. On one hand, the influence of European Colonial empires was replaced by that of Japan and America; on the other hand, the decline of the control from European Colonial empires contributed to the rise of people's self-awareness in Asian colonies.

Facing these changes, the Taiwan Industrial Exhibition held by the Japanese government was opened in Taipei in 1916 in order to review their ruling efforts and to encourage the Japanese to invest in and emigrate to this island. In addition, the conflicts between the colonial authorities and people could be eased. The Taiwan Industrial Exhibition became the first venue to demonstrate Taiwan to Japan and other countries following Japan's seizure of Taiwan twenty years earlier.

\subsection{In the Taiwan Exhibition}

With the rapid developments in the following twenty years, various exhibitions in different locations, on varying scales, and to a range of target audiences were held in Taiwan. It was proposed that a larger exhibition should be held to demonstrate the ruling achievement and to celebrate the $40^{\text {th }}$ anniversary of the Japanese colonization of Taiwan. On October $10^{\text {th }}$ 1935, the greatest exhibition, called Taiwan Exhibition, was opened in Taipei associated with island-wide exhibitions in other cities and towns. When the opening ceremony ended with a fireworks display, about 15,000 pigeons, and fighter planes overhead, the Exhibition was formally opened and crowded with thousands of visitors. During the fifty days of the exhibition, the main site in Taipei was visited by $2,738,895$ people $^{3}(\mathrm{Lu}$, 2005).

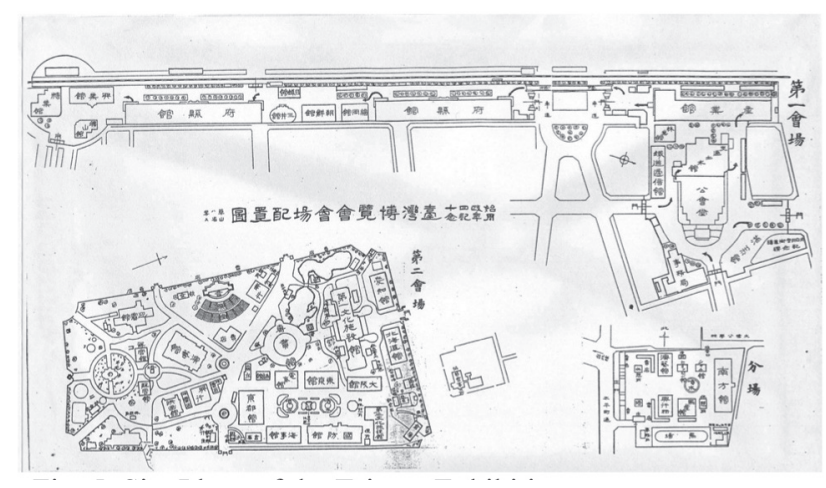

Fig.5. Site Plans of the Taiwan Exhibition

(Source: Honda Yu Taro, 1935)

Within this exhibition, there were two main categories of exhibition hall, halls of "Official Operation", which were designed and operated directly by the government, and halls for "Special Purpose", which were built by private associations with official support. The former included the halls for industry, transportation and civil engineering, prefectural affairs, encouraging new industry, culture, defense, and tourism, etc... The latter comprised firstly, pavilions for representing industries of Taiwan, such as the sugar industry, forestry, electricity, transportation and so on; secondly, pavilions for introducing the industries of Japan, and finally the halls for demonstrating local features and souvenirs in Japan as well as her other colonies, Korea and Manchuria to compare the colonial developments with that in Taiwan.

Geographically, the exhibition in the city area was divided into two main sites, the First Site and the Second Site, as well as a subsidiary site in Da-DaoCheng. The west boulevard, originally designed as a three-lined road for the movement of vehicles and pedestrians, was temporarily turned into a longitudinal exhibition site, the First Site. When entering the First Site, from north to south, the visitor saw the Hall of Manchuria first. Next the Public Assembly Hall, which played a central role in this exhibition, was on the right-hand side. Next to this was the Hall of Transportation and Civil Engineering, followed in order by the Hall of Industry, the first Hall of Prefectural Affairs, the Halls of Fukuoka, Korea and the second Hall of Prefectural Affairs. Finally, the visitor saw the Halls of Encouraging New Industry, 


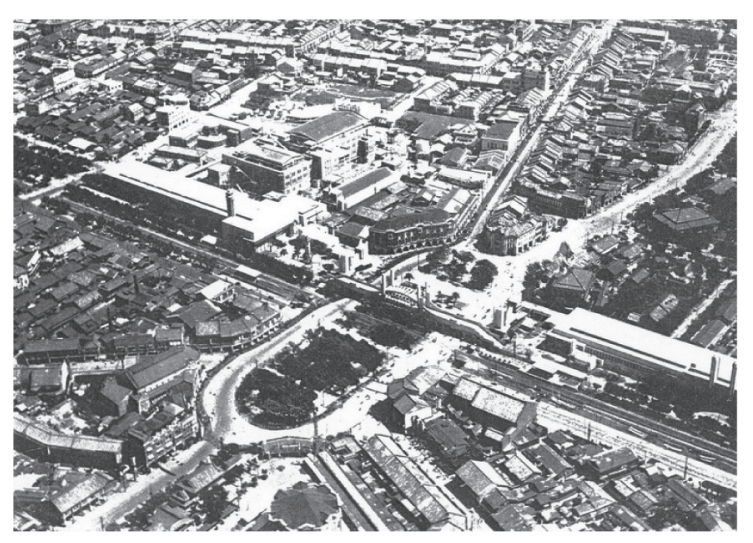

Fig.6. Arial View of the First Site (Source: Honda Yu Taro, 1935)

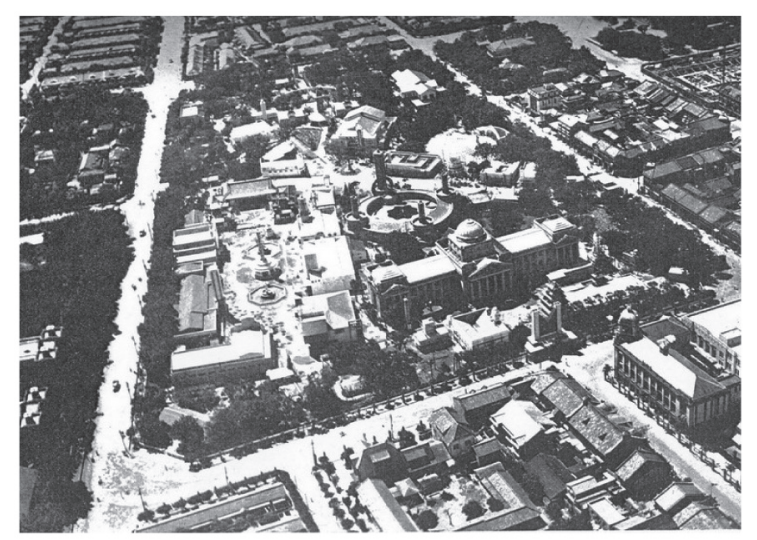

Fig.7. Arial View of the Second Site (Source: Honda Yu Taro, 1935)

Sugar Industry and The Hall of Mines.

By spatial effects, the layout of the First Site demonstrated the successful governance of Japanese colonization. Within it, the halls of "Official Operation" were all about topics on ruling achievements in Taiwan. The Hall of Industry included all the constructions and development in Taiwan while the Halls of Prefectural Affairs were symbols of territories of Japan. The visitor could experience the differences between the colony and the colonial state.

Taipei Park, chosen as the Second Site, was rearranged, and new plants were grown. The Second Site incorporated the First and the Second Halls of Culture, the Hall of Defense, and pavilions of electricity, Nagoya, Hokkaido, Tokyo, Kyoto, Osaka, together with the Theater, the Cinema House and the Musical Hall. The Taiwan Museum, which was transformed into the First Cultural Hall, displayed the process of educational modernization.

In addition, several thoroughfares of the city and Da-Dao-Cheng area were decorated with colorful celebration arches and lanterns to promote a festival atmosphere. Meanwhile at the subsidiary site in DaDao-Cheng, the visitor saw the Hall of South Asia, the Philippines, Thailand and Fu-Jian. There was also the House of the Horse, which incorporated some shops. With these, the colonial authority asserted not only the ruling intention in Taiwan, but also high interest in Southeast Asia.

Among these halls, the Public Assembly Hall ${ }^{2}$ was designed in transitional style, "modern eclectic style" (Fu, 1999:76). Moreover, many pavilions were in ArtDeco style which was extremely popular at that time. Popular originally in the 1920s and 30s, "Art-Deco" took its name from an exhibition held in Paris in 1925, the Exposition Internationale des Arts Décoratifs et Industriels Modernes. It followed with a number of other styles: the straight lines and the decorative highly sculptural elements (Bayer, 1992:12). From the main gate of the First Site, the wing-like façade with straight lines, similar to the Hall of Transportation in the Chicago Exposition, expressed an attitude shifting from the past to the future. In addition, the asymmetrical arrangement of space of the exhibition halls, for example Halls of the Sugar Industry and Encouraging New Industry, were not only arranged asymmetrically, but also designed in Art Deco style with straight lines and sculptural elements.

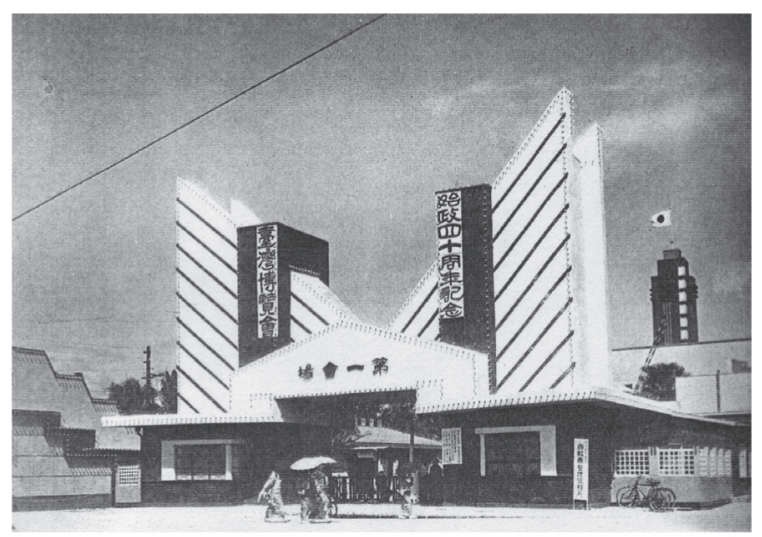

Fig.8. The Main Gate of the First Site (Source: Honda Yu Taro, 1935)

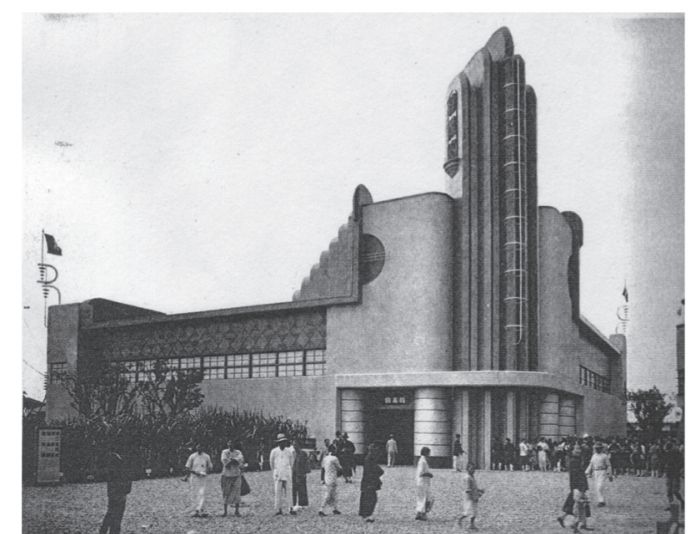

Fig.9. The Hall of Sugar Industry (Source: Honda Yu Taro, 1935)

\subsection{Thinking about the Taiwan Exhibition}

Visited by almost three million people, the sites were successfully transformed into urban stages for performing this panoramic dream. In an urban context, the transformation of urban space especially around 
the main sites was significant. Similarly to the Great Exhibition in London, the main sites were selected in the center of the city. For example, the west three-lined boulevard, where had previously been the city wall during the Qing Dynasty, was temporarily turned into a longitudinal exhibition site as the First Site.

Moreover, particularly in the First Site, the layout of the exhibition halls, from the hall of Industry to the Halls of Encouraging New Industry, represented not only an axis of progress from present to future, but also the successful colonial governance in Taiwan. The Second Site in the Taipei Park was obviously planned to convey the concepts of cultural awareness and material consumption. In other words, the arrangement of these pavilions revealed the intention of the colonial government to propagandize the advanced development in Japan.

Architecturally, except for some exhibition halls (Halls of Fu-Jian, Thailand and Korea etc.), the Japanese government tried to avoid adopting a traditional construction style for the exhibition. Instead, the design of most exhibition halls represented a trend toward modernism. It was believed to be affected by the exhibition of Chicago in 1933, named "Century of Progress Exposition: Chicago" (Lu, 2005). Moreover, the application of lighting and colors was a major characteristic of the exhibition. By using them, the exhibits and specimens attracted a large number of visitors. Those exhibition halls with lights became the brightest landmarks during the night and created phantasmagoric illuminations in this colonial city.

Although the exhibition attracted many people and created a fantastic effect, the disaffection among the intellectuals was still apparent. The real thoughts and responses of Taiwanese people could be inferred from songs, novels or diaries. In a song in Taiwanese 'The New Song of Visiting the Exhibition by Man and $\mathrm{Wife}^{\mathrm{i}}$, the layout and exhibits were recorded in detail, while lively atmosphere of this exhibition was also described. It presented the pursuit of pleasure for the public in this temporary festival venue. However, certain people took different viewpoints regarding this event. In his short story entitled A Letter in Autumn, Dian-Ren Zhu (1936), a Taiwanese writer in the Japanese colonial period, described the mental state of Mr Dou-Wen, an adherent and scholar of the Qing Dynasty, while visiting the Taiwan Exhibition. He wrote:

The exhibition has been opened for more than ten days ... Once you go to the capital city for the exhibition, you will be much more delighted than visiting the moon....

...the road in front of the Taipei Railway Station is overflowing with people going towards the museum, therefore Mr. Dou-Wen feels like a lonely boat without destination. (Zhu, 1936)

Contrary to the positive image propagandized by the colonial authority, Zhu's novel described the exhibition in a negative way. "Let's go to visit the Taiwan Exhibition!" became a popular phrase at that time. However, for him, Taipei city was only a model of modernity, which was completely manipulated by foreign powers. Therefore, going to Taipei was not only for the Taiwan exhibition, but also to appreciate the modern and progressive achievement of Japanese colonization:

Sir! I guess you are not a native here. No wonder you did not know that the former site of Fu Yamen (The Office of Qing Dynasty's Provincial Commissioner in Taiwan) was replaced by the Public Assembly Hall. What!?....

...While Facing the Fu Yamen, which has been moved into a new site in the botanical garden, Mr. Dou-Wen was thinking about the thriving and prosperous past. Now, it feels so lonely! Everything was gone! ... (ibid)

Through the character Mr. Dou-Wen, a scholar and adherent of the Qing Dynasty, Zhu tried to present the conflict between the traditional and modern as well as past and present world. In Mr. Dou-Wen's eyes, the Taiwan exhibition was not a celebration of progress and development but a phantasmagoria of modernity without self-awareness and self-identity.

\section{Conclusion}

From the Great Exhibition to the Taiwan Exhibition, there seem to be unexpected similarities between these two spatial venues in completely different times, 1851 and 1935, and places, the west and the east. Both exhibitions revealed much more than the original concepts of a world exhibition, which concerned innovation and consumption.

In the Great Exhibition, the Crystal Palace presented a new industrial technology of architecture and became an archetype of the world exhibition. In the Palace, all the exhibits and models displayed formed an axis of progress as well as a symbol of "modernity". However, its underlying ambitions such as imperialism and colonialism were naturally revealed. In brief, within the exhibition, it linked private associations, government offices, public institutions, consumers and tourists. Moreover, it contributed to creating the idea and the form of Great Britain and her other colonies.

The Taiwan Exhibition, postdating the Great Exhibition by almost eighty years, conveyed a stronger intention to display the ideology of colonialism rather than "modernity". As the largest exhibition held in the Japanese colonies, the Taiwan Exhibition became a specific venue for the Japanese authorities to communicate two ideas to the Taiwanese people: the successful colonial governance as well as civilization and enlightenment. However, the arrangement of exhibition halls within the main sites reflected a representation of "heterotopias of deviation" between 
the colony and the empire (Lu, 2002).

All in all, through these two cases, "modernity" and "colonialism" have been shown to be primary concepts when discussing world exhibitions in the nineteenth and the early twentieth centuries. As Hoffenberg (2001: 277) points out, "exhibitions produced not only momentary results, but also long-term legacies at the personal and collective levels." Especially for those people in colonized areas, modernity, colonialism and colonial modernity will be an on-going issue to discuss in every aspect of their history.

\section{Notes}

This work was supported by National Science Council of Taiwan under project No. NSC92-2211-E-006-083.

1) Prince Albert's speech at the Lord Mayor's banquet in honor of the Great Exhibition, quoted in Commission of the Great Exhibition. See: Hvattum (2004:126)

2) The Taipei Public Assembly Hall was built in 1931 and completed in 1935 for celebrating the coronation of Showa Emperor.

3) The Taiwan Exhibition in Taipei and others cities in Taiwan was in total visited by $3,346,972$ people. The sites in Taipei were visited by $2,738,895$ people.

4) 'The New Song of Visiting the Exhibition by Man and Wife' was published by Yu-Jhen Han Book's Section, Chia-Yi in 1936. See: Lu (2005: 409-423).

\section{References}

1) Bayer, P. (1992) Art Deco Architecture: Design, Decoration and Detail from the Twenties and Thirties. London: Thames and Hudson Ltd.

2) Beaver, P. (1970) The Crystal Palace1851-1936: A Portrait of Victorian Enterprise. London: Hugh Evelyn Limited.

3) Barlow, T.E. (1997) Formations of colonial Modernity in East Asia. Durham \& London: Duke University Press.

4) Berman, M. (1982) All That Is Solid Melts Into Air. New York: Penguin Books.

5) Çelik, Z. (1992) Displaying the Orient: Architecture of Islam at Nineteenth-Century World's Fairs. Berkley and Los Angeles: University of California Press.

6) Chen, F.-M. (2004) Colonial Modernity: Historical and Literary Perspectives on Taiwan. Taipei: Rye Field Publications.

7) Ching, L.T.S. (2001) Becoming "Japanese": Colonial Taiwan and the Politics of identity Formation. London: University of California Press.

8) Frisby, D. (2001) Cityscapes of Modernity. Malden: Blackwell Publishers Inc.

9) Frisby, D. (2004) 'Analyzing Modernity: Some Issues' In Mari Hvattum \& Christian Hermansen (Eds.), Tracing Modernity: Manifestations of the Modern in Architecture and the City. New York: Routledge.

10) Fu, C.-C. (1999) The Taiwanese Architecture in Japanese Colonial Period (1895-1945). Taipei: Da-Di Publishers

11) Hoffenberg, P.H. (2001) An Empire on Display: English, Indian, and Australian Exhibitions from the Crystal Palace to the Great War. Berkeley and Los Angeles: University of California Press.

12) Honda, Y.T. (Ed.) (1935) The Record of Taiwan Architecture, 7(5) (6). Taipei: Architectural Institute of Taiwan.

13) Gilloch, G. (1997) Myth \& Metropolis: Walter Benjamin and the City. Malden: Blackwell Publishers Ltd.

14) Hobhouse, H. (2002) The Crystal Palace and The Great Exhibition: Art, Science and Productive Industry. London: The Athlone Press.

15) Hvattum, M. (2004) 'A complete and universal collection: Gottfried Semper and the Great Exhibition. In Mari Hvattum \& Christian Hermansen(Eds.), Tracing Modernity: Manifestations of the Modern in Architecture and the City. New York: Routledge.

16) Kanomata, M. (Ed.) (1939). The Record of the Taiwan Exhibition for the 40th Anniversary of Japanese Colonization of Taiwan. Taipei: The Taiwan Exhibition for the 40th Anniversary of Japanese Colonization of Taiwan.

17) King, A.D. (1976) Colonial Urban Development Culture, Social Power and Environment. London: Routledge \& Kegan Paul.

18) Lo, S.-W. (1996) 'A Palimpsest of Faits Urbains in Taipei City: Wall/Boulevard/Fair/Squatters/Shopping Blocks'. In The Collections of Papers in the Second Conference of Architectural Theories and Applications. Taichung: Department of Tung-Hai University.

19) Lu, S.-L. (2002). Exhibition Colonial Taiwan: Taiwan Pavilion and the Fifth National Exhibition for Encouraging Trade and Industry at Osaka, 1903, Taiwan Historical Research, 9 (2): pp.103-144.

20) Lu, S.-L. (2005) Exhibiting Taiwan:Power, Space and Image Representation of Japanese Colonial Rule. Taipei: Rye Field Publications.

21) Mattie, E. (1998) World's Fairs. New York: Princeton Architectural Press.

22) Peattie, M.R. (1984) Japanese Attitude toward Colonialism, 1895-1945. In Ramon H. Myers \& Mark R. Peattie (Eds.), The Japanese Colonial Empire, 1895-1945. Princeton: Princeton University Press.

23) Shin, Gi-Wook Shin \& Robinson, Michael. (1999) Rethinking Colonial Korea. In, Gi-Wook Shin \& Michael Robinson (Eds.), Colonial Modernity in Korea. Cambridge (Massachusetts) and London: Harvard University Press.

24) Wesemael, Pieter van.(2001) Architecture of Instruction and Delight: A Socio-historical Analysis of World Exhibition as a Didactic Phenomenon (1798-1851-1970). Rotterdam: OIO Publishers.

25) Zhu, D.-R. (1936) 'A Letter in Autumn'. Collection of ShiLang Wang's and Dian-Ren Zhu's Novels. Taipei: Avant-garde Publishers.

26) University of Maryland Libraries. (2000)[Online] Available: http:// www.lib.umd.edu/ARCH/exhibition/home.html(21/01/06). 